\title{
CDKN2A deletion in supratentorial ependymoma with RELA alteration indicates a dismal prognosis: a retrospective analysis of the HIT ependymoma trial cohort
}

\author{
Stephanie T. Jünger ${ }^{1,8} \cdot$ Felipe Andreiuolo ${ }^{1} \cdot$ Martin Mynarek $^{2} \cdot$ Inken Wohlers $^{3,9} \cdot$ Sven Rahmann $^{3}$. \\ Ludger Klein-Hitpass $^{4}$ - Evelyn Dörner ${ }^{1} \cdot$ Anja zur Mühlen ${ }^{1} \cdot$ Natalia Velez-Char $^{1} \cdot$ Katja von Hoff $^{2}$. \\ Monika Warmuth-Metz ${ }^{5} \cdot$ Rolf-Dieter Kortmann $^{6} \cdot$ Beate Timmermann $^{7} \cdot$ Andre von Bueren $^{2,10} \cdot$ Stefan Rutkowski ${ }^{2}$. \\ Torsten Pietsch ${ }^{1}$ [D
}

Received: 30 April 2020 / Revised: 24 May 2020 / Accepted: 25 May 2020 / Published online: 8 June 2020

(c) The Author(s) 2020

Pediatric supratentorial ependymomas with RELA fusions (RELA-EP) have been identified as a unique novel tumor entity $[9,10]$. Fusions between C11orf95 and RELA pathologically activate the NFKB signaling pathway indicated by nuclear accumulation of p65-RelA. Deletions of CDKN2A encoding the negative cell-cycle regulator p16 have been described in a subset of supratentorial ependymomas, associated with worse outcome $[2,5,7]$. We assessed the frequency and prognostic impact of $C D K N 2 A$ deletions in a cohort of 54 RELA-EP in children treated according to HIT2000-E protocols (for detailed demographic information, see supplementary materials and methods and supplementary table 1).

High-resolution, genome-wide copy number profiles were generated by molecular inversion probe (MIP) assay. Chromosomal breaks were identified within the C11orf95 and

Electronic supplementary material The online version of this article (https://doi.org/10.1007/s00401-020-02169-z) contains supplementary material.

Torsten Pietsch

t.pietsch@uni-bonn.de

1 Department of Neuropathology, Institute of Neuropathology, DGNN Brain Tumor Reference Center, University of Bonn, Venusberg-Campus 1, 53127 Bonn, Germany

2 Department of Pediatric Hematology and Oncology, University Hospital Hamburg-Eppendorf, Hamburg, Germany

3 Genome Informatics, Institute of Human Genetics, University of Duisburg-Essen, Essen, Germany

4 Department of Cell Biology (Tumor Research), University of Duisburg-Essen, Essen, Germany

5 Institute of Diagnostic and Interventional Neuroradiology, University Hospital Würzburg, Würzburg, Germany
RELA genes corresponding to fusion transcripts (Fig. 1a, d). All cases showed pathological nuclear accumulation of p65-RelA as a hallmark of RELA-EP (Fig. 1f). Homozygous deletion (complete loss) of CDKN2A was detected in 9 of 54 (16.7\%) cases (Fig. 1c); and 8 of these (88.9\%) showed a concordant complete loss of p16 protein (Fig. 1g). In one case, few tumor cells expressed p16 protein indicating retained $C D K N 2 A$ alleles in single cells. Fourteen cases (25.9\%) harbored a hemizygous deletion of $C D K N 2 A$. In these, p16 protein was retained in $92.9 \%$ of cases testedone case lacked p16 protein expression indicating the inactivation of the second allele by alternative mechanisms. Thirty-one of 54 cases (57.4\%) had no deletion of CDKN2A; all showed p16 protein expression (Fig. 1h). Immunohistochemistry for $\mathrm{p} 16$, therefore, may serve as a surrogate for complete $C D K N 2 A$ loss, but cannot differentiate between hemizygous and wild-type status. There was no statistical association between $C D K N 2 A$ deletions and mitotic activity as previously described in $I D H$-mutant glioma [1]. The

6 Department of Radiation Oncology, University Hospital Leipzig, Leipzig, Germany

7 Westdeutsches Protonentherapiezentrum, Essen, Germany

8 Present Address: Department of Neurosurgery, University of Cologne Medical Center, Cologne, Germany

9 Present Address: Medical Systems Biology Division, Lübeck Institute of Experimental Dermatology and Institute for Cardiogenetics, University of Lübeck, Lübeck, Germany

10 Present Address: Division of Pediatric Hematology and Oncology, Department of Pediatrics, Obstetrics and Gynecology, University Hospital of Geneva, Geneva, Switzerland 

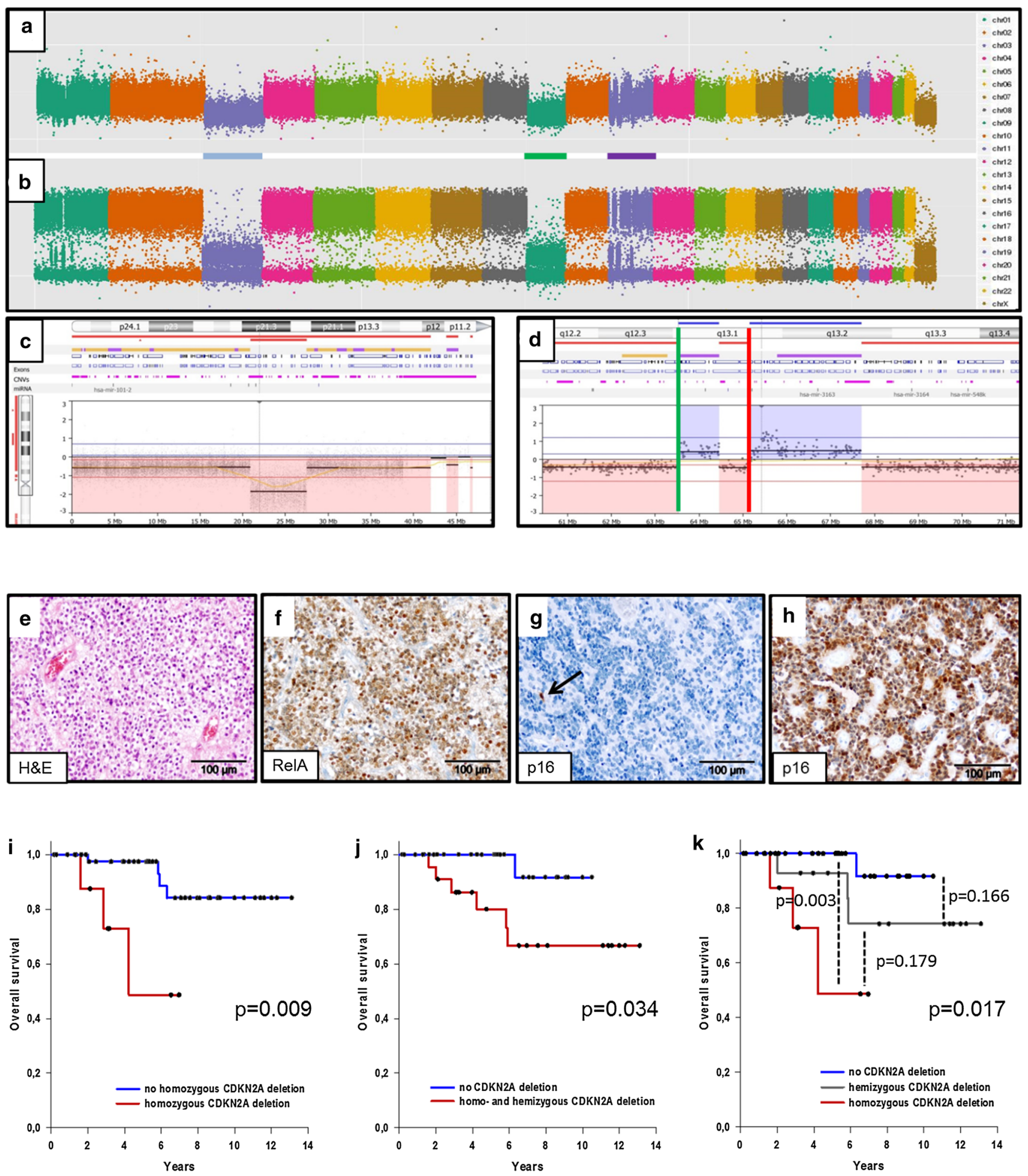

Fig. 1 a Genomic copy number profile and b allele distribution (MIP) of a RELA-EP showing chromothripsis of chromosome 11; $\mathbf{c}$ case with homozygous $C D K N 2 A$ deletion; $\mathbf{d}$ case showing breaks in C11orf95 (green bar) and RELA (red bar); e clear cell morphology; f nuclear p65-RelA; $\mathbf{g}$ case with homozygous $C D K N 2 A$ deletion/loss of p16 protein (arrow, endothelial cell as internal positive control); $\mathbf{h}$ case without $C D K N 2 A$ deletion/retained p16; i-k Kaplan-Meier analysis, impact of $C D K N 2 A$ deletions on OS 
presence of $C D K N 2 A$ deletions (homo- or hemizygous) correlated with higher age at diagnosis in line with the literature $[3,5,8]$. CDKN2A deletion may also occur as secondary event in tumor progression [7].

To identify possible differences between RELA-EP with versus without $C D K N 2 A$ deletion on the transcript level, 12 RELA-EP were analyzed by RNA sequencing for differentially expressed genes. After correction for multiple testing, five genes were found significantly downregulated including $C D K N 2 A$ and $C D K N 2 B$ and their neighboring gene MTAP ( $S$-methyl-5'-thioadenosine phosphorylase) located in the deleted region. MTAP is a key enzyme in the methionine salvage pathway. Its deletion leads to dependence on the activity of the methyltransferase PRMT5 [6] which can be blocked by PRMT5 inhibitors as interesting novel therapeutics in MTAP deleted tumors. In addition, KIF7 (15q26) encoding a cilia-associated protein and ZNF536 (19q12) encoding a neuronal marker were found downregulated. GABRA2 (4p12) encoding the gamma-aminobutyric acid receptor subunit alpha-2 was found highly upregulated in CDKN2A deleted tumors (supplementary figure 3).

Kaplan-Meier analysis revealed a significant correlation between $C D K N 2 A$ deletions and overall survival status (OS). Different groups were compared: (1) homozygous $C D K N 2 A$ deletion vs. hemizygous $C D K N 2 A$ deletion and tumors with two retained alleles $(p=0.009)$; (2) homoor hemizygous $C D K N 2 A$ deletions vs. tumors with two retained alleles $(p=0.034)$ and (3) all three strata separately $(p=0.017)$ (Fig. 1i-k). In contrast to Korshunov et al. [5], neither homozygous nor hemizygous deletion showed prognostic relevance regarding EFS (supplementary figure 2). Predominant clear cell morphology as a histological feature was a favorable prognosticator for OS $(p=0.039)$, and high mitotic activity ( $>17$ mitoses/10HPF) was a predictor for tumor relapse $(p=0.004)$ as well as OS $(p=0.007)$ (supplementary figure 1). Multivariate analysis confirmed mitotic activity as independent prognostic indicator for EFS (supplementary table 2).

Our data show that deletions of $C D K N 2 A$ represent an objective parameter for risk stratification in RELA-EP. Molecular inversion probe methodology turned out to represent a sensitive and quantitative tool for $C D K N 2 A$ assessment in FFPE material. Apart from ependymoma, homozygous deletions of $C D K N 2 A$ have recently been described as adverse prognostic marker for other CNS tumors, including anaplastic $I D H$-mutant gliomas and $B R A F$-mutant low-grade gliomas $[1,4,11]$. The deletion/inactivation of $C D K N 2 A$ may result in a pathological activation of cyclin-dependent kinases $4 / 6$ targetable by specific inhibitors such as palbociclib. Therefore, $C D K N 2 A$ inactivation in
RELA-ependymomas may represent a potential therapeutical target.

Acknowledgements Open Access funding provided by Projekt DEAL. Funding was provided by Deutsche Kinderkrebsstiftung (Grant nos. DKS 2006.03, 2009.19, 2011.01 and 2014.17). We thank Dr. Steffen Albrecht, Montreal, for critical reading of the manuscript.

Open Access This article is licensed under a Creative Commons Attribution 4.0 International License, which permits use, sharing, adaptation, distribution and reproduction in any medium or format, as long as you give appropriate credit to the original author(s) and the source, provide a link to the Creative Commons licence, and indicate if changes were made. The images or other third party material in this article are included in the article's Creative Commons licence, unless indicated otherwise in a credit line to the material. If material is not included in the article's Creative Commons licence and your intended use is not permitted by statutory regulation or exceeds the permitted use, you will need to obtain permission directly from the copyright holder. To view a copy of this licence, visit http://creativecommons.org/licenses/by/4.0/.

\section{References}

1. Appay R, Dehais C, Maurage C-A et al (2019) CDKN2A homozygous deletion is a strong adverse prognosis factor in diffuse malignant IDH-mutant gliomas. Neuro-oncology 21:1519-1528

2. Bortolotto S, Chiadò-Piat L, Cavalla P et al (2001) CDKN2A/p16 in ependymomas. J Neurooncol 54:9-13

3. Hirose Y, Aldape K, Bollen A et al (2001) Chromosomal abnormalities subdivide ependymal tumors into clinically relevant groups. Am J Pathol 158:1137-1143

4. Korshunov A, Casalini B, Chavez L et al (2019) Integrated molecular characterization of IDH-mutant glioblastomas. Neuropathol Appl Neurobiol 45:108-118

5. Korshunov A, Witt H, Hielscher T et al (2010) Molecular staging of intracranial ependymoma in children and adults. J Clin Oncol 28:3182-3190

6. Mavrakis KJ, McDonald ER 3rd, Schlabach MR et al (2016) Disordered methionine metabolism in MTAP/CDKN2A-deleted cancers leads to dependence on PRMT5. Science 351:1208-1213

7. Milde T, Pfister S, Korshunov A et al (2009) Stepwise accumulation of distinct genomic aberrations in a patient with progressively metastasizing ependymoma. Genes Chrom Cancer 48:229-238

8. Nowak J, Jünger ST, Huflage H et al (2019) MRI phenotype of RELA-fused pediatric supratentorial ependymoma. Clin Neuroradiol 29:595-604

9. Parker M, Mohankumar KM, Punchihewa C et al (2014) C11orf95-RELA fusions drive oncogenic NF- $\mathrm{\kappa B}$ signalling in ependymoma. Nature 506:451-455

10. Pietsch T, Wohlers I, Goschzik T et al (2014) Supratentorial ependymomas of childhood carry C11 orf95-RELA fusions leading to pathological activation of the NF- $\mathrm{BB}$ signaling pathway. Acta Neuropathol 127:609-611

11. Ryall S, Zapotocky M, Fukuoka K et al (2020) Integrated molecular and clinical analysis of 1,000 pediatric low-grade gliomas. Cancer Cell 37:569-583

Publisher's Note Springer Nature remains neutral with regard to jurisdictional claims in published maps and institutional affiliations. 